\title{
Improved Coal Feeding Control System of Thermal Power Plant Based on PLC
}

\author{
Chi Zhou ${ }^{1 *}$, Ruicai $\mathrm{Si}^{1}$ and Songhan Wang ${ }^{1}$ \\ ${ }^{1}$ Jilin Electric Power Research Institute Co., Ltd
}

\begin{abstract}
Based on PLC, the improved coal feeding system of thermal power plant is developed, which solves the problems of poor timeliness and inaccurate quantity of coal feeder. In the process of belt transportation, a dynamic coal feeding rate is established. By controlling the coal feeding rate and then controlling the running speed of the belt, a certain amount of coal is supplied to the thermal power plant, so as to provide more accurate coal, improve the corresponding timeliness, and have better economic benefits.
\end{abstract}

\section{Introduction}

According to statistics, China has long been dominated by thermal power generation, and thermal power generation will reach more than $70 \%$ of the total power generation in 2020[1]. The improved coal feeding system can not only improve the power generation efficiency of thermal power plants, but also ensure the rational use of coal, and has good economic benefits.

\section{System composition}

\subsection{System core}

Coal feeder is the key mechanical equipment in the automatic loading system of coal preparation plant. Its main function is to control the quantity of coal according to the demand of coal quantity in the buffer bin, and transport the coal to the buffer bin by belt conveyor. When the loading system works, the automatic control system of the coal feeder must have accurate quantitative, accurate control and perfect protection functions to ensure the safe, continuous and stable operation of the automatic quantitative loading system. Most of the coal feeders in the automatic quantitative loading system of domestic coal preparation plants are controlled by relay or single chip microcomputer, and the weighing mode is traditional electronic weighing. Under the harsh working environment of coal preparation plants, the weighing accuracy and real-time control of this scheme are poor, and the failure rate is high, which seriously affects the loading speed and accuracy of the automatic quantitative loading system. In order to solve the above problems, PLC control technology and frequency conversion technology are introduced into the automatic control system of coal feeder to improve the automation and intelligent level of coal feeder.

The composition of the improved coal feeding control system is shown in Figure 1. PLC controller is the core, and the coal feeder is controlled in real time according to the signal input by AI module. AI signal mainly includes weighing signal, belt speed signal and material level signal. The above three sensor signals participate in the automatic control process of the coal feeder. The lower computer uses PLC to collect the instantaneous coal quantity and instantaneous speed, and combines with the material level signal verification to prevent coal fault. According to the input required by the power plant coordination control, the instantaneous coal feeding rate is obtained through algorithm calculation, combined with PID The algorithm can adjust the belt transportation speed more accurately, so as to control the coal transportation volume, realize the quantitative coal feeding, and send the working status, parameter information and fault information to the monitoring platform by means of communication, so as to facilitate the operators to grasp the operation information of the coal feeder in time. 


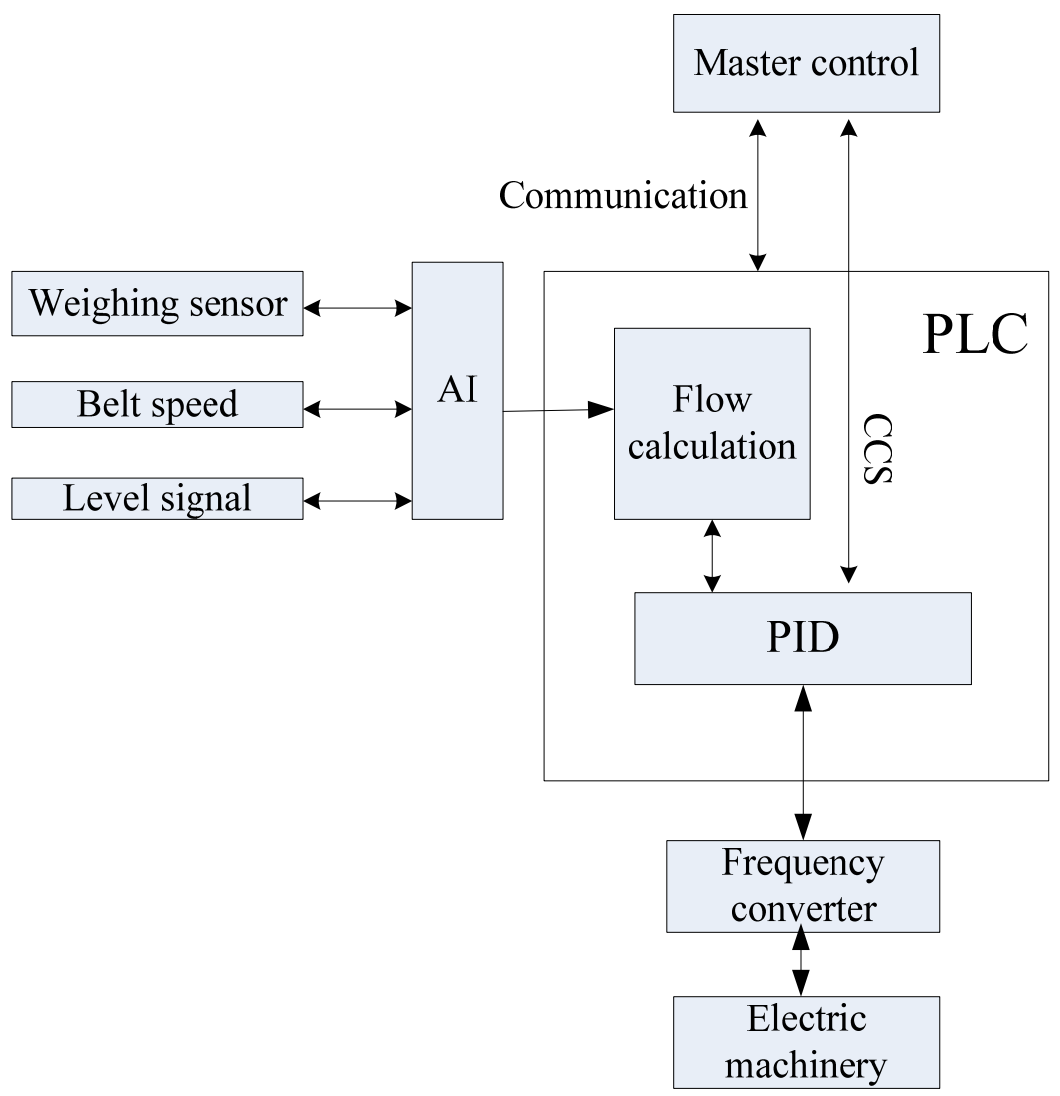

Figure 1. Schematic diagram of system quantitative coal feeding

\section{2 hardware composition}

The control core of the system is SIMATIC S7-300 compact CPU. The PLC supports various communication modes, such as TCP / IP, Modbus TCP, Modbus RTU and other communication extensions. It can interact with a variety of DCS systems[2]. Other hardware includes communication module IM361, The power supply PS307 and AI module SM331 AI8 * 12bit, the main equipment calculates the instantaneous coal feeding rate and outputs the command according to the master control coordination command and the actual analog signal[3].

The weighing sensor adopts CYB-606s cantilever beam weight measuring module, which has a close structure, and includes transmission device in addition to the weight measuring sensor. The weighing accuracy reaches $0.1 \%$. It is easy to connect with the original belt and is easy to install. The material level signal is introduced by the signal in the bin. The belt speed sensor adopts photoelectric speed sensor, and the circuit adopts modular design, and the volume is small. The inverter adopts Delta VFD-M440. The control method of the inverter includes frequency control method and closed loop vector control. The protection action includes low voltage protection, over-current protection, short circuit protection and DC bus overvoltage protection[4]. The frequency converter communicates with PLC directly with USS protocol[5].

\subsection{Program design of coal feeding system}

The coal feeding system shall be switched from remote to local, and the motor can be operated in positive/reverse direction to prevent coal transportation from sticking. The first start system can carry out zero point calibration and range verification to reduce belt weight error. After the above work, quantitative coal feeding can be carried out. According to the data calculated by the main control coordination control (CCS), the coal feeding rate is obtained by comparing with the actual coal feeding quantity measured, and the coal feeding rate at the next moment is obtained. The frequency converter is controlled by PID algorithm and the motor speed is controlled. The system shall have protection action, and the fault will stop automatically. The coal conveying belt shall be opened before the coal feeder. If it is not operated according to the steps, it shall be forbidden to start. There is a locking relationship between the coal feeder and the belt conveyor: when starting, the belt conveyor must be started first, and then the coal feeder, so as to prevent the belt conveyor from not starting after starting the coal feeder, which leads to the leakage of coal transported to the belt conveyor, when stopping, the coal feeder must be stopped first, and then the belt conveyor must be stopped after a certain interval of time, To prevent the belt conveyor from stopping first and the coal feeder from unloading coal, resulting in the leakage of coal transported to the belt conveyor. There is a locking relationship between the 
buffer bin and the coal feeder: when the level indication of the buffer bin reaches the highest level, in order to prevent the overflow of the buffer bin, the stop signal of the coal feeder must be given to stop the operation of the coal feeder. When the coal feeder detects that the level indication of the buffer bin reaches the highest level, it cannot be started. The material level signal is accumulated at all times and then introduced to PLC algorithm module to compare the actual coal feeding quantity to reduce the deviation of coal feeding.

After the system starts and completes the initialization process, it is ready to start the coal feeder. If the coal feeder equipment is normal, start the coal feeder, if the equipment is abnormal, give an alarm and give a fault prompt. After the coal feeder starts and runs smoothly, the key parameters of the coal feeder are measured. If speed regulation is needed, the speed is calculated according to the position of buffer bin and the load bearing of belt conveyor. After the target value of speed regulation is calculated, the frequency converter is controlled by PLC controller to adjust the speed to the target value, if speed regulation is not needed, the coal feeder runs smoothly according to the predetermined speed. The operation flow chart is shown in Figure 2.

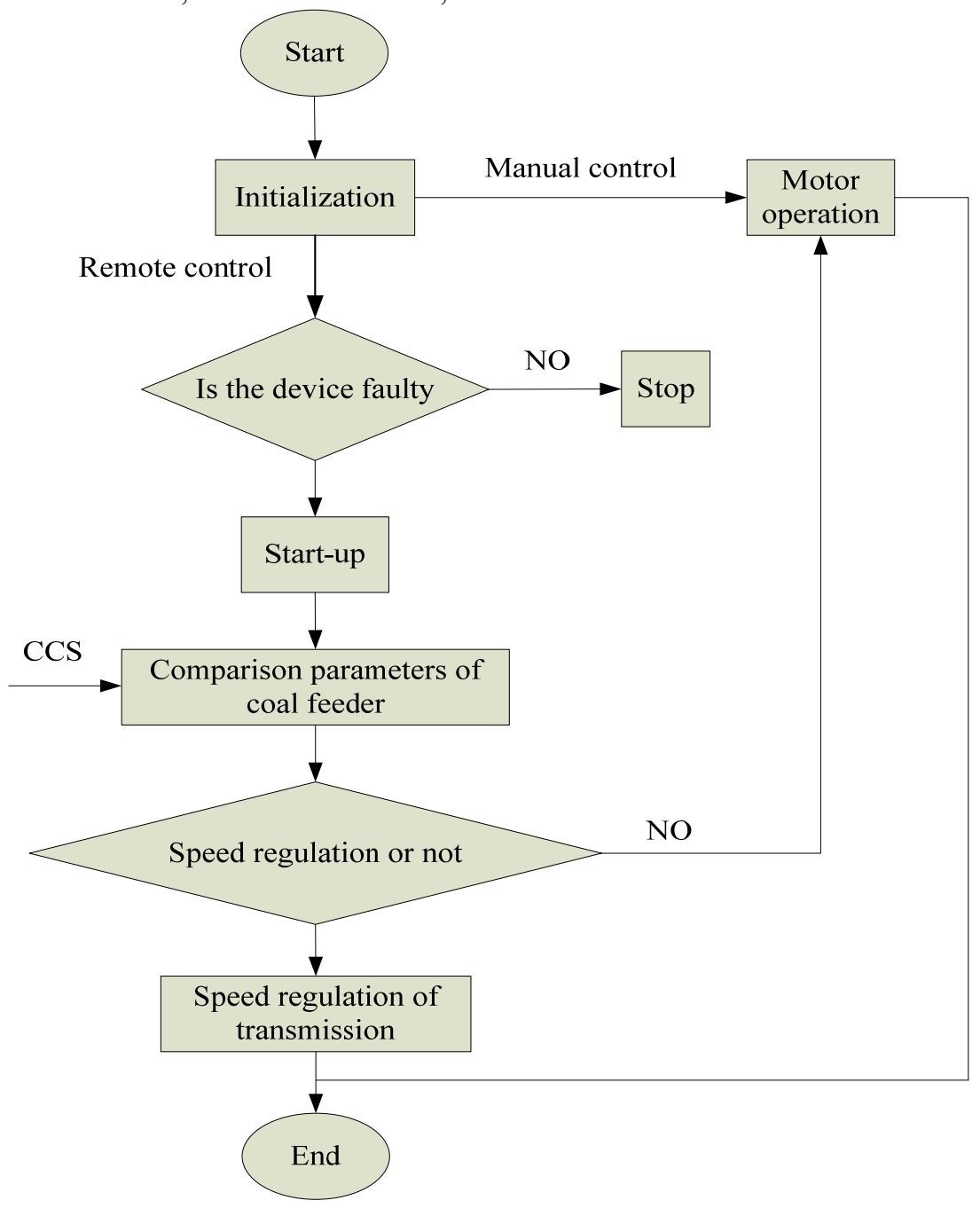

Figure 2. Program flow chart of coal feeding system

\section{Summary}

The design of improved coal feeding control system in thermal power plant based on PLC mainly uses PLC to control the speed of coal feeder motor, and finally realizes the coal quantity adjustment of the system, so as to realize the effective control of power generation. Compared with the previous coal weighing system, it is of great significance to save energy, improve economic benefits and ensure safety. The safety and reliability of the whole system have been improved. After transformation, the operation of the system has reached the predetermined requirements of economy and benefit. The research and application of the automatic control system of coal feeder has a positive significance for the automation and intelligent process of coal handling in power plant.

\section{Acknowledgments}

Thanks to the leaders and colleagues around me for their encouragement and support, so that my thesis can be successfully completed. This article is a phased achievement of the State Grid Jilin Electric Power 
Research Institute youth innovation competition power supply center. If there is any thoughtless part in this article, please criticize and correct it.

\section{References}

1. Wang D, Li H, Wang C, et al. (2021) Thermodynamic analysis of coal-fired power plant based on the feedwater heater drainage-air preheating system. Applied Thermal Engineering, 185:116420.

2. Berger, H.. (2001). Automating with Step 7 in Lad and Fbd: Programmable Controllers Simatic S7-300-400 with Cdrom and Disk. John Wiley \& Sons, Inc.

3. Berger, H.. (1999). Automating with Simatic: Integrated Automation with Simatic S7-300/400 Controllers. John Wiley \& Sons, Inc.

4. Sun, Z., Yang, Y., Hu, J., \& Yan, H.. (2015). Design of the intelligent braking system with PLC based on the USS interface protocol. 2015 IEEE 19th International Conference on Computer Supported Cooperative Work in Design (CSCWD). IEEE.

5. Lam, C.. (2010). Participant response system with facilitated communications bandwidth. 